\title{
Staphylococcemia due to Cosmetic Doping: An Important Etiology of Fever of Undetermined Origin
}

\section{Ronísie Duarte de Oliveira ${ }^{1^{*}}$, Raquel Rodrigues Ferreira Rocha de Alencar ${ }^{2}$, Bruno Vianei Real Antonio $^{3}$, André Luiz Tiúba Mendonça ${ }^{2}$ and Aryadine Allinne Machado de Miranda ${ }^{4}$}

${ }^{1}$ Internal Medicine Resident, Nilton Lins Hospital (HNL), State of Amazon, Brazil

${ }^{2}$ Medicine Student, Faculty of Medicine of Federal University of Amazonas (UFAM), State of Amazon, Brazil

${ }^{3}$ Physician Graduated, Faculty of Medicine of Federal University of Amazonas (UFAM), State of Amazon, Brazil

${ }^{4}$ Rheumatologist, Municipal Health Secretary (SEMSA), State of Amazon, Brazil

*Corresponding author: Ronísie Duarte de Oliveira, Internal Medicine Resident, Nilton Lins Hospital (HNL), Pedro Teixeira Avenue, n. 25, Dom Pedro. 69040-000, Manaus City, State of Amazonas, Brazil, Tel: +5592-99108-8450

\begin{abstract}
Introduction: A new problem, called cosmetic doping, has been inserted globally for some decades, and has grown in importance in Brazil in recent years, affecting athletes and non-athletes. The cosmetic doping consists in the use of oily substances by the intramuscular route to increase volumetrically the muscle, which can lead to the formation of oil deposits in the muscle, called oleomas, necrosis, physical deformities and even death.

Case description: We present a 31-year-old male patient who sought the emergency room with a complaint of daily fever for 5 months of sudden onset, intermittent character, higher temperature at night, ranging from 38 to $39{ }^{\circ} \mathrm{C}$, associated with weight loss of approximately $12 \mathrm{~kg}$ in 2 months, arthralgia and severe myalgia in deltoids, calves, and glutes, which made it impossible to walk and abduct the upper limbs. The present case report discusses the case of this patient hospitalized in the city of Manaus, state of Amazonas, Brazil, to investigate the etiology of fever of undetermined origin, later attributed to the intramuscular application of oily substances.
\end{abstract}

Conclusions: Early identification and diagnosis of this condition by the health care team is fundamental to provide a better prognosis and lesser functional damage to the affected individual.

\section{Keywords}

Cosmetic doping, Fever of undetermined origin, Staphylococcemia

\section{Introduction}

The search for aesthetics and bodily perfection is growing worldwide. The abuse of androgenic anabolic steroids is already recognized as a major worldwide problem of substance abuse involving tens of millions of individuals, of whom about $98 \%$ are men under 50 years of age [1]. However, a new problem, called cosmetic doping, has been inserted globally for some decades, and has grown in importance in Brazil in recent years, affecting athletes and non-athletes [1].

These are systematic injections of oily substances by the intramuscular route, known as $A D E$, a veterinary product containing fat soluble vitamin $A, D$ and $E$, indicated for the treatment of vitamin deficiency and infection in cattle and horses. According to manufacturers, animals should receive no more than 5 $\mathrm{mL}$ for a period of 120 days. It is known that ADE users apply a quantity four times higher per application in each member, with weekly repetitions $[1,2]$.

ADEs are applied in oily vehicles (vegetable, mineral and animal oils), in order to increase volumetrically the muscle [1]. This increase, however, is not related to muscular hypertrophy or any physiological adaptive event, as occurs with anabolic steroids, having only cosmetic effect and resulting in the deformity of its

Citation: de Oliveira RD, de Alencar RRFR, Antonio BVR, Mendonça ALT, de Miranda AAM (2019) Staphylococcemia due to Cosmetic Doping: An Important Etiology of Fever of Undetermined Origin. Clin Med Rev Case Rep 6:263. doi.org/10.23937/2378-3656/1410263

Accepted: April 11, 2019: Published: April 13, 2019

Copyright: (C) 2019 de Oliveira RD, et al. This is an open-access article distributed under the terms of the Creative Commons Attribution License, which permits unrestricted use, distribution, and reproduction in any medium, provided the original author and source are credited. 
original appearance [1]. The use of these substances can lead to the formation of oil deposits in the muscle, called oleomas [3], necrosis, physical deformities and even death [1].

Case reports on cosmetic doping have been found describing consequences of intramuscular application of sunflower oil, synthol (consisting of $85 \%$ of oil, $7.5 \%$ of lidocaine, $7.5 \%$ of alcohol) (consists of $85 \%$ of oil, $7.5 \%$ of lidocain, $7.5 \%$ of alcohol) [4] and paraffin oil, which showed a clinical picture composed mainly of remarkable weight loss, phlogistic signs and deformity in the area of the injection, painless lymphadenopathy and laboratory examinations showing increased infection parameters, such as leukocytosis with neutrophilia [57]. However, no published cases of cosmetic doping describing patients' reports of fever have been found.

The objective of this article is to report the case of a patient hospitalized at the Tropical Medicine Foundation - Doctor Heitor Vieira Dourado in Manaus, Amazonas, Brazil, to investigate fever of undetermined origin, attributed to the intramuscular application of oily substances.

\section{Case Description}

A 31-year-old male patient sought the emergency room of Tropical Medicine Foundation's Doctor-Heitor Vieira Dourado on January $3^{\text {rd }}, 2018$, complaining of a daily fever for 5 months of sudden onset, intermittent character, with elevated body temperature at night, ranging from 38 to $39{ }^{\circ} \mathrm{C}$, without improvement with symptomatic, associated with chills, sweating and weight loss of approximately $12 \mathrm{~kg}$ in 2 months.

He also complained of arthralgia, constant holocranial headache and myalgia in deltoids, calves, and glutes. According to the patient, muscle pain made it impossible to walk and abduct the upper limbs. It relates the most recent episode of fever, on December $27^{\text {th }}, 2017$, to intense muscular effort. The patient was hospitalized for diagnostic elucidation and vancomycin was started at 1 $\mathrm{g}$ intravenously every 12 hours for 14 days.

Data from the patient's chart showed previous hospitalization on November $16^{\text {th }}, 2017$, with similar symptoms. In November he also presented dry cough, chest pain, nausea, vomiting and bloody diarrhea, being diagnosed with typhoid fever. He was treated with ciprofloxacin 400 mg every 12 hours intravenously for 14 days without improvement. It evolved with worsening of pain in deltoids, calves and glutes on November $28^{\text {th }}, 2017$, being performed soft tissue ultrasonography showing cellulitis, receiving oxacillin 2 g every 6 hours, intravenously for 10 days. Patient was discharged with improvement.

The physical examination showed adenomegaly in the axillary, supraclavicular and inguinal region, painful and with fibroelastic consistency. In addition, hardened edema was observed with phlogistic signs in deltoids, calves and left gluteus. Chest examination revealed diffuse rude vesicular murmur and decreased expansibility. The nonspecific laboratory tests results are listed below (Table 1).

Table 1: Nonspecific laboratory tests results and reference values.

\begin{tabular}{|l|l|l|}
\hline Laboratory test & Results & Reference Values \\
\hline Red blood cells & $4.04 \mathrm{million} / \mathrm{mm}^{3}$ & 4.3 to $6 \mathrm{million} / \mathrm{mm}^{3}$ \\
\hline Hemoglobin & $11 \mathrm{~g} / \mathrm{dl}$ & 13.5 to $17.3 \mathrm{~g} / \mathrm{dl}$ \\
\hline Hematocrit & $34 \%$ & 41 to $54 \%$ \\
\hline Leukocytes & $15.240 / \mathrm{mm}^{3}$ & 3.600 to $11.000 / \mathrm{mm}^{3}$ \\
\hline Promyelocytes & $4 \%$ & 0 to $0 \%$ \\
\hline Mielocytes & $6 \%$ & 0 to $0 \%$ \\
\hline Metamielocytes & $4 \%$ & 0 to $0 \%$ \\
\hline Eosinophils & $11 \%$ & 1 to $5 \%$ \\
\hline Lymphocytes & $15 \%$ & 20 to $50 \%$ \\
\hline Platelets & $627.000 / \mathrm{mm}^{3}$ & 150.000 to $400.000 / \mathrm{mm}^{3}$ \\
\hline Reticulocyte count & $3.61 \%$ & 0.5 to $2 \%$ \\
\hline Lactate Dehydrogenase & $466.5 \mathrm{U} / \mathrm{L}$ & 200 to $480 \mathrm{U} / \mathrm{L}$ \\
\hline Alkaline Phosphatase & $167 \mathrm{U} / \mathrm{L}$ & 27 to $100 \mathrm{U} / \mathrm{L}$ \\
\hline Gamma-glutamyltransferase & $265.9 \mathrm{U} / \mathrm{L}$ & $<55 \mathrm{U} / \mathrm{L}$ \\
\hline TGO/AST; TGP/ALT & $55 \mathrm{U} / \mathrm{L} ; 65.7 \mathrm{U} / \mathrm{L}$ & up to $40 \mathrm{U} / \mathrm{L} ;$ up to $41 \mathrm{U} / \mathrm{L}$ \\
\hline VHS & $83 \mathrm{~mm}$ & 1 to $18 \mathrm{~mm}$ \\
\hline PCR & $318.66 \mathrm{mg} / \mathrm{L}$ & $<8 \mathrm{mg} / \mathrm{L}$ nonreactive and $\geq 8 \mathrm{mg} / \mathrm{L}$ reactive \\
\hline Prothrombin Time and Activity (PAT) & $16.4 \mathrm{~seconds}$, activity: $53 \%$ & $12.5 \mathrm{~seconds}=100 \%$ \\
\hline INR & 1.40 & 1.0 \\
\hline
\end{tabular}

The table above demonstrates nonspecific laboratory tests results of the patient in investigation of fever of undetermined origin and its reference values. 


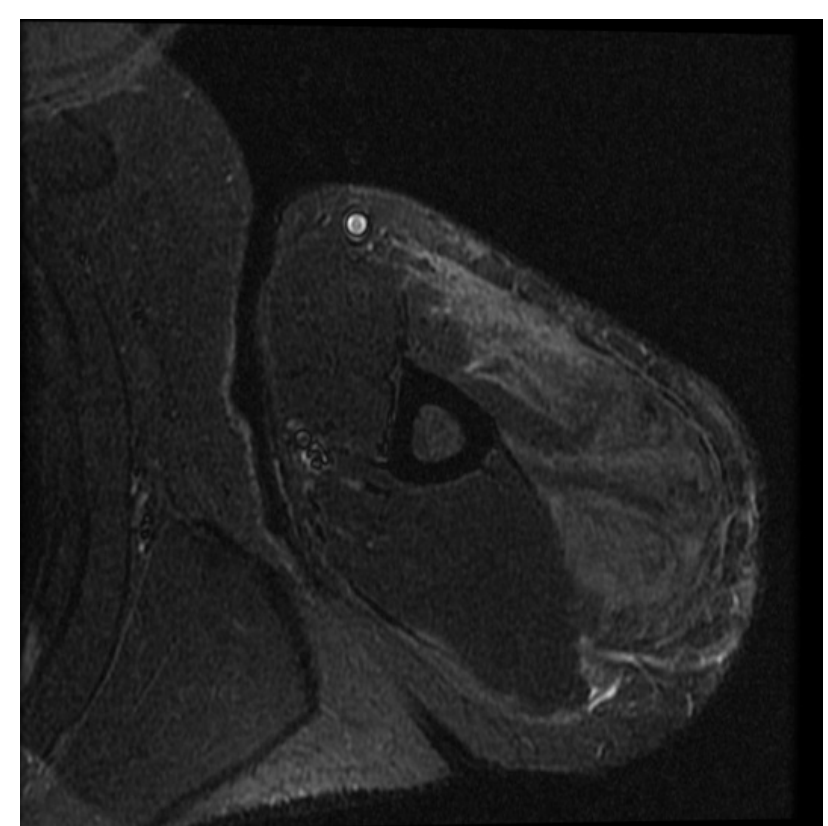

Figure 1: Magnetic resonance imaging of the left shoulder demonstrating heterogeneous tissue, with laminar areas of fat signal diffusely infiltrated in the deltoid muscle.

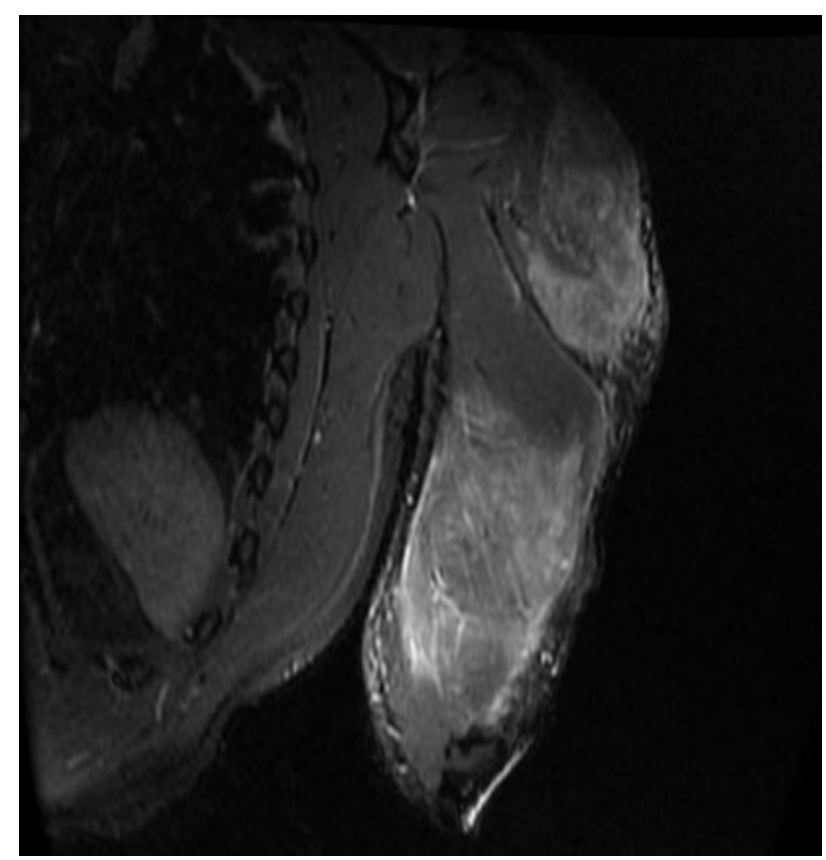

Figure 2: Magnetic resonance imaging of the left arm demonstrating heterogeneous tissue, with laminar areas of fat signal diffusely infiltrated in the muscles deltoid, middle and lower thirds of the fibers of the long head of the triceps and in the anterior fibers of the biceps, with volumetric increase of the muscular belly.

Infectious diseases, such as malaria, hepatitis and syphilis, neoplasia and autoimmune disorders like systemic lupus erythematosus, polymyositis and thyroiditis, were investigated. However, laboratory tests, blood culture and imaging exams aimed at those diseases were negative.

A magnetic resonance imaging of upper limbs realized on January $11^{\text {th }}, 2018$ demonstrated heteroge- neous tissue, with laminar areas of fat signal diffusely infiltrated in the muscles deltoid, middle and lower thirds of the fibers of the long head of the triceps and in the anterior fibers of the biceps, with volumetric increase of the muscular belly. Besides, the exam identified focuses of oedema and fat infiltrating the subcutaneous plane in the arms as well as enhancement of the adjacent subcutaneous plane and the mentioned muscular bellies, indicating an inflamatory component. There is no significant purulent collection in the study. There is, however, some infiltration of the deltoid's lateral fibers in its distal section next to the umeral insertion, findings compatible with injection of exogenous intramuscular material (Figure 1 and Figure 2).

\section{Conclusions}

By taking into account the clinical-laboratorial correlation and the imaging exams, infectious, neoplastic and rheumatological diseases were excluded, which established the chronic intramuscular application of oily substances by the patient as the cause of the fever of unknown origin [8]. After being questioned, the patient confirmed that he has utilized various oily substances and anabolic steroids since he was 12-years-old, such as nandrolone, stanozolol, testosterone, drostanolone, mesterolone and others.

A case report that described the development of skin and muscle necroses after paraffin oil intramuscular injections by a male patient says that the clinical features of paraffin oil injection consists in 3 phases: The initial symptom (an acute inflammatory phase 1-6 months after injection), a latent phase (during which the substance is tolerated) and, after a variable time-interval, late reactions appear [5]. Another study about the clinical and radiologic manifestations of breast oleoma in a male patient following sunflower oil injection affirms that self-injection with contaminated material produces an acute suppurative panniculitis with concomitant systemic symptoms [7]. Additionally, this inflammatory process may cause chronic granulomatous inflammation and fibrosis, since the oil substance is resistant to the action of lysosymal enzymes of tissues and macrophages $[5,7]$. These supracited facts explain the febrile condition of the patient in this report, since chronic granulomatous diseases, usually as a result of the persistence of a non-degradable product and of active cell mediated hypersensitivity, often present with fever [9].

In Brazil, studies on the profile of oily substances and anabolic steroid users seeking cosmetic results indicate that they are mainly young men with low income and education level. A brazilian study whose objective were to determine the degree of knowledge of bodybuilders users of oils of local application on this practice and to draw a socioeconomic profile of these users verified that its sample of 45 users were between 18 and 32 (average of $23.1 \pm 3.7$ ) years old. The same study demonstrated that $78.8 \%$ of those surveyed lived in 
peripherical neighbourhoods and only one athlete had completed higher education [10]. Body dissatisfaction due to comparison with the 'standard' body type, fear of exclusion by their peeps and the symbolic capital associated to a muscular body are the main reasons for an athlete to utilize inadequate ways in the attempt of reaching an ideal body [11].

About the therapeutic conduct, on the $7^{\text {th }}$ January 2018 the medical team started a treatment with vancomycin $500 \mathrm{mg}$ and meloxicam $15 \mathrm{mg}, 1$ tablet a day orally for 9 days and warm compresses on the affected muscles every 6 hours. On the $10^{\text {th }}$ January 2018, ceftriaxone $2 \mathrm{~g}$ for endovenous use once a day for 7 days was associated to the previous scheme. The patient continued using vancomycin $500 \mathrm{mg}$ until the $19^{\text {th }}$ January, 2018, when it was suspended. Tenoxicam $20 \mathrm{mg} 1$ tablet every 12 hours for 7 days was then added to the prescription.

A case report about a patient who injected non-specified oily substances in her buttocks and thighs described the attempt of treating ulcers and tumoral lesions in the application areas with cephalexin for 6 months and prednisone $40 \mathrm{mg}$ a day for 2 months. With no good results, the medical team decided to initiate a treatment with tetracycline $500 \mathrm{mg}$ a day every 6 hours orally and the lesions receded in 4 months, leaving only hyperchromic scars as remaining signs [12]. Another case report states that the use of compressive bandaging therapy by a patient who used injectable paraffin can be useful for oedema reduction and microcirculation enhancement [5].

In ratifying the antimicrobial conduct utilized in the patient of this report, the literature indicates the use of vancomycin to treat systemic infections caused by Staphylococcus aureus, such as staphylococcemia. If a vancomycin resistant strain is suspected, an alternative is to associate vancomycin with a beta-lactam antibiotic [13]. Staphylococcemia was suspected due to the port of entry consequential to the percutaneous oily substances applications, which probably were realized without appropriate asepsis and shared storage flasks. Infection due to lack of asepsis at the site of application is reported in the literature as a complication of injections of ADEs and other oils [1].

The patient progressed with recovery from the fever, myalgia, arthralgia and phlogistic signals in the deltoids, buttocks and calves, and was able to walk and move the upper limbs. On the $20^{\text {th }}$ January, 2018, the patient was discharged and to continue his treatment with meloxicam $7.5 \mathrm{mg}, 1$ tablet a day for 14 days, monitoring kidney function every 7 days and a referral to an orthopedist.

The clinical recognition of intramuscular applications of injectable oil is realized through inspection in extreme users, when an evident disproportion between body parts, local deformation and a small peak in the musculature are present. By palpating the area, one can notice a cyst inside the muscular belly, even when the muscle is relaxed. Imaging exams such as ultrasonography, computerized tomography and magnetic resonance imaging can be utilized to evaluate the damage [1].

Early identification and diagnosis of this condition by the health care team is fundamental to provide a better prognosis and lesser functional damage to the affected individual.

\section{Acknowledgments}

The authors' would like do thank the patient for consent the publication of the case, internal medicine residence program from Nilton Lins Hospital, the Tropical Medicine Foundation - Doctor Heitor Vieira Dourado and the Federal University of Amazonas.

\section{Conflict of Interest Statement}

The authors declare no conflits of interest.

\section{Financial Support}

The authors didn't have any financial support.

\section{Sources of Support}

This work had no sources of support.

\section{Statement of Equal Authors' Contribution}

All authors have a statement of authorship responsibility. Ronísie Duarte de Oliveira was the doctor responsible for the diagnostic investigation and therapeutic conduct of the presented patient, as well as guided and reviewed the writing of the case. Raquel Rodrigues Ferreira de Alencar had a role in helping the diagnostic investigation, in the conception of the work and its writing and revision. Bruno Vianei Real Antonio had a substantial contribution in the development and writing of the manuscript, as well as in the review of the literature and in the interpretation of data. André Luiz Tiúba Mendonça contributed in the development and writing of the manuscript, interpretation of data, review of the literature and in the translation from portuguese to english process. Aryadine Allinne Machado de Miranda revised it critically for important intellectual content and had the final approval of the version to be published.

\section{References}

1. Figueiredo VC, Silva PRP, Trindade RS, Rose EH (2011) Doping cosmético: A problemática das aplicações intramusculares de óleos. Rev Bras Med Esporte 17: 5661.

2. De Francesco Daher E, Mesquita Martiniano LV, Lopes Lima LL, Viana Leite Filho NC, de Oliveira Souza LE, et al. (2017) Acute kidney injury due to excessive and prolonged intramuscular injection of veterinary supplements containing vitamins A, D and E: A series of 16 cases. Nefrologia 37: 61-67. 
3. Dejanovic D, Loft A (2017) 18F-FDG PET/CT findings following repeated intramuscular injections of "Site Enhancement Oil" in the upper extremities. Clin Nucl Med 42: e436-e437.

4. Pupka A, Sikora J, Mauricz J, Cios D, Plonek T (2009) The usage of synthol in the body building. Polim Med 39: 63-65.

5. Iversen L, Lemcke A, Bitsch M, Karlsmark T (2009) Compression bandage as treatment for ulcers induced by intramuscular self-injection of paraffin oil. Acta Derm Venereol 89: 196-197.

6. Ghandourah S, Hofer MJ, Kiessling A, El-Zayat B, Schofer MD (2012) Painful muscle fibrosis following syntho injections in a bodybuilder: A case report. J Med Case Rep 6: 248.

7. Sarica O, Kayhan A, Demirkurek HC, Igdem AA (2016) Subcutaneous Oleomas Following Sunflower Oil Injection: A Novel Case and Review of Literature. J Breast Health 12 : 141-144.

8. Lambertucci JR, Ávila RE, Voieta I (2005) Febre de origem indeterminada em adultos. Rev Soc Bras Med Trop 38: 507-513.

9. James DG (2000) A clinicopathological classification of granulomatous disorders. Postgraduate Medical Journal 76: $457-465$

10. Ferreira UMG, Gouveia RLB, Mimbacas A, Sena JE, Gurjão LA (2012) Utilização de óleos de aplicação local intramuscular para fins estéticos por praticantes de musculação. Motricidade 8: 647-658.

11. Iriart JAB, Chaves JC, Orleans RG (2009) Culto ao corpo e uso de anabolizantes entre praticantes de musculação. Cad. Saúde Pública 25: 773-782.

12. Magrin PF, Ribeiro CD, Filho LP, Durães SM, Rochael MC (2010) Oleoma: Relato de caso com boa resposta à tetraciclina. Dermatol Online J 16: 7.

13. Santos AL, Santos DO, Freitas CC, Ferreira BLA, Afonso IF, et al. (2007) Staphylococcus aureus: Visitando uma cepa de importância hospitalar. J Bras Patol Med Lab 43: 413-423. 